2019

\title{
Parts of the Whole: Theories of Pedagogy and Kolb's Learning Cycle
}

Dorothy Wallace

Dartmouth College, dorothy.wallace@dartmouth.edu

\section{Recommended Citation}

Wallace, Dorothy. "Parts of the Whole: Theories of Pedagogy and Kolb's Learning Cycle." Numeracy 12 , Iss. 1 (2019): Article 17. DOI: https://doi.org/10.5038/1936-4660.12.1.17 


\title{
Parts of the Whole: Theories of Pedagogy and Kolb's Learning Cycle
}

\author{
Abstract \\ This essay argues that discussions of pedagogy for quantitative reasoning will be more useful when \\ framed in terms of overarching theories of learning. As an example, Kolb's Learning Cycle theory \\ encompasses a range of teaching methods and places them in a context that can help instructors make \\ practical decisions about the timing and emphasis of various methods. The theory also suggests \\ research questions that would test its validity or refine its utility for instructors. This essay aims to assist \\ readers of Numeracy to frame and carry out research in best practices for teaching quantitative \\ reasoning.

\section{Keywords} \\ pedagogy, learning theory, Kolb's Learning Cycle, numeracy, quantitative reasoning \\ Creative Commons License \\ (c) (i) \& \\ This work is licensed under a Creative Commons Attribution-Noncommercial 4.0 License

\section{Cover Page Footnote} \\ Dorothy Wallace, Contributing Editor of Numeracy, is a professor of mathematics at Dartmouth. She has \\ broad background in many kinds of mathematics, with numerous publications in pure, applied, and \\ educational topics. Her recent research papers in mathematical biology include some 30 undergraduates \\ among her coauthors. She was a charter board member of the National Numeracy Network and was a \\ founding co-editor of this journal.
}




\title{
Parts of the Whole
}

\author{
A Column by D. Wallace
}

The problem of how best to improve the numeracy of a society is a thorny one, addressing the learning process of a single student but rising in scale to include the management and alteration of an entire system of education. With the issue of quantitative literacy always in mind, this column will consider various aspects of the systemic workings of education: the forces acting on classrooms, teachers, and students and mechanisms of both stasis and change. With the issues of volume 9, the column has grown to include thoughts on pedagogy, in addition to continuing to explore strategies for systemic change in quantitative education.

\section{Theories of Pedagogy and Kolb's Learning Cycle}

Now that the value of quantitative reasoning and the need for education that addresses quantitative literacy are well established in educational circles, it seems reasonable to spend some effort addressing pedagogical approaches that would make quantitative education as effective as possible. One could make a strong case (although I won't do it here) that shortcomings in the pedagogy of several disciplines (science, social science, math) have led to the need for a separate effort in quantitative literacy. Having made space in our institutions for this effort, we want exemplary teaching to make it the best it can possibly be.

I have a personal interest in the process of learning new ways to teach. For decades, my department has required graduate students to take an intensive course, which we just call "the teaching seminar," on the teaching and learning of mathematics. In this double credit course, students read and discuss educational research and theory, use that theory to construct approaches and lesson plans for short "math camps" at the high school level, and then offer these camps to students in the community. The course was initially designed by Claudia Henrion, Marcia Groszek, and myself and was subsequently improved upon by several others, especially Ken Bogart and Alex Barnett. As instructors of both math and teaching, we cared about educational theory only if we could make sense of it in the classroom.

One of the resources we regularly use in the teaching seminar is a popular book about teaching by J. E. Zull (2002). Perhaps the most useful aspect of this book is its user-friendly introduction to the theory of the "Learning Cycle" that was originally proposed by David Kolb (Kolb and Fry 1974, 1975). Kolb's original article and his many subsequent related papers have been extensively 
cited, discussed, critiqued and modified across many domains. Instructors of the teaching seminar have found it useful in various ways.

In this article, we will look at the practical utility of educational theory, how this utility plays out in the special case of Kolb's Learning Cycle, and how the learning cycle suggests classroom experiments that may improve our teaching of quantitative reasoning.

\section{The Value of Theory}

Although science is sometimes described as the process of testing hypotheses through controlled experiments, observational data, or natural experiments, the reality is more complex, because a hypothesis has to come from somewhere. Scientific theory usually underlies hypotheses that generate useful experiments or data collection and analysis. Similarly, theories of learning underlie hypotheses about how to teach effectively.

Philip Kitcher describes three properties of a useful theory (Kitcher 1982, 45-48). One is explanatory power-a theory should have the ability to unify a variety of observations as the consequence of a single schema. The second is fecundity - a good theory should suggest new ideas of what to look for and how to test hypotheses. The third property of a useful theory is the presence of auxiliary hypotheses that can be tested independently of the theory's main claims. "Fads" in education are approaches to teaching that are utilized for a while and then discarded (Paul and Elder 2007). A good theory should illuminate not only the reasons why but also the conditions under which a certain approach might be effective as well as the conditions under which it should be discarded. It should suggest new approaches and be useful across multiple teaching contexts and levels. It may suggest adjustments that would make a particular approach more useful. These adjustments could be framed as hypotheses that are testable by experiment to measure any improvement.

Of course, there is value in specific instructional methods also, but a method that (for example) delivers optimal instruction of a related rates problem to a group of twenty-five Dartmouth first-year students does not necessarily transfer to teaching a different subject, to a class of a different size, or at a different institution. A good theory, on the other hand, has legs.

\section{Kolb's Learning Cycle}

Kolb proposes a theory of learning that requires four parts comprising a cycle that can be repeated indefinitely. The cycle is generally framed as follows: Having a concrete experience (1) is followed by reflection on that experience (2), which is followed again by abstract analysis and conclusions (3), which leads finally to actions that test these conclusions (4). Zull points out that these four stages correspond simplistically and loosely to parts of the brain that are engaged in 
taking in sensory data (1), processing that data (2), planning an action (3), and carrying out that action (4). Thus, what Kolb describes as "concrete experience," Zull reinterprets as "listening to the lecture" or "reading the text." In any case this interpretation still leaves three more parts of the cycle that must be addressed in other ways. Sometimes students in the teaching seminar get quite angry at Zull for his oversimplification of brain science or his facile interpretation of concrete experience. Disagreement and even anger are pedagogically useful because every teacher has to develop their own working interpretation of the cycle if that teacher plans to use it productively. If reading Zull is step one in the learning cycle, the annoyed students are already engaged in step 2.

Many other readings in the teaching seminar, such as those on active learning, make much more sense in light of Kolb's cycle. It is no longer a question of which is better-lecture or active learning. Both are necessary and satisfy different objectives. The learning cycle theory unifies many proposed teaching methods. Rather than pitting them against each other, it asks how they fit into the cycle. The theory explains why certain educational experiments fail: testing a method that addresses one part of the learning cycle while omitting the others should not improve student learning overall, no matter how good that particular approach is at the specific thing it attempts to do. Kolb's learning cycle has enormous explanatory power. It integrates many teaching methodologies, or "fads" into a coherent whole, the first requirement of a good theory.

Awareness of the learning cycle actually makes it more difficult to design lessons, because one becomes more aware of the ways in which a lesson falls short. How do you get students to reflect upon something and analyze it abstractly, without doing it for them? What even counts as abstraction for a particular problem? When you design an in-class worksheet, is the goal to help students process new knowledge, plan an action, or carry an action out? Or all three? If, for example, a spreadsheet is provided that easily elicits the correct entries and conclusions from the students, did they really experience any reflection, analysis, or planning at all? How could you design an assessment that would answer that question? The learning cycle suggests these questions, as well as many others. It satisfies the requirement of fecundity given by Kitcher.

Even in the short time frame of the teaching seminar, auxiliary hypotheses become apparent. One of these has to do with pace. In the seminar, we challenge students to analyze teaching methods and lesson plans in light of this learning cycle, however they come to interpret it. They are asked to create lesson plans based on the cycle with various time frames - the whole cycle to be completed in class, overnight, or within the week. Changing the pace at which one progresses through the cycle makes for very different sorts of lesson plans and probably very different learning experiences. Along with pace is timing. Do all parts of the cycle require similar time frames? And how do you manage a group of students passing 
through this cycle at different rates? These are practical questions but of course the literature has plenty of theoretical elaborations on the learning cycle as well (see, e.g., Bergsteiner, Avery, and Neumann 2010; Bergsteiner and Avery 2014; Schenck and Cruickshank, 2015).

In short, Kolb's learning cycle theory satisfies the criteria for both a good scientific theory and a good educational theory. It unifies many proposed hypotheses for effective teaching. It suggests many experiments that would refine our understanding of what each part of the cycle entails, in a variety of contexts. It also supports many auxiliary hypotheses about how, in practice, to carry out teaching in this way.

\section{Learning Cycle Experiments in QL Courses}

If discussions of quantitative reasoning are to expand to include pedagogy, it would be useful to frame these discussions with learning theories such as Kolb's that encompass a wide variety of teaching techniques. In this section I will discuss basic research questions in QL stemming from Kolb's theory, along with discussion of the kinds of details that would make such research useful to teachers of the subject.

The most obvious question is whether taking the learning cycle into account when structuring QL courses or lessons helps the students learn. To determine this, one could take two topics of comparable difficulty in a standard QL course with a single instructor and teach one exactly the same way as last year, while teaching the other with a lesson based on the learning cycle. The research design would have to include some proof that (last year) the two topics were indeed of comparable difficulty to the students. It would have to delineate the extent to which last year's lesson ignored parts of the learning cycle and took others into account. It would have to specify how these were taken into account in the experimental lesson. It would have to justify the means by which "learning" is assessed. The results, which we hope would be submitted to Numeracy, would also include the authors' interpretation of the learning cycle and the actual lesson plans and assessments used, for the benefit of other instructors.

If an instructor's teaching style already reflects the learning cycle, there are still numerous experiments to be made. Pacing is always an issue. Is it better to pass through one or more iterations of the cycle in a single class period? Can the cycle move slowly over days, weeks, months, or even years? How does learning differ when this pace is varied? Another interesting question involves group versus individual work. At which points in the learning cycle does group work improve learning, and at which points is individual work more productive? And does the answer to this question vary across topics? A third question might involve the use of QL topics that elicit strong emotions, such as criminal acts or political or environmental issues. Can we measure the extent to which emotions 
assist or damage the learning in various parts of the cycle? These are all rather general questions that would have to be specified for a particular course and student population.

To summarize, I am arguing that it would be beneficial for the QL movement to engage in discussions of pedagogy, that these discussions will be more productive if guided by rich theories, and that good theories will provide a basis for educational research particular to QL and extremely useful to the readers of Numeracy.

\section{References}

Bergsteiner, H., and G. C. Avery. 2014. "The Twin-Cycle Experiential Learning Model: Reconceptualising Kolb's Theory. Studies in Continuing Education 36 (3): 257-274. https://doi.org/10.1080/0158037X.2014.904782.

Bergsteiner, H., G. C. Avery, G. C., and R. Neumann. 2010. "Kolb's Experiential Learning Model: Critique from a Modelling Perspective." Studies in Continuing Education 32 (1): 29-46. https://doi.org/10.1080/01580370903534355.

Kitcher, P. 1982. Abusing Science: The Case Against Creationism. Cambridge: The MIT Press

Kolb, D. A., and R. E. Fry. 1974. "Toward an applied theory of experiential learning." Working paper, MIT Alfred P. Sloan School of Management.

Kolb, D. A., and R. E. Fry. 1975. "Toward an applied theory of experiential learning." In Theories of Group Processes, edited by C. L. Cooper, Chapter 3. New York: Wiley.

Paul, R. and L. Elder, L. 2007. A Critical Thinker's Guide to Educational Fads: How to Get Beyond Educational Glitz and Glitter. Foundation for Critical Thinking, http://www.criticalthinking.org/

Schenck, J., and J. Cruickshank. 2015. "Evolving Kolb: Experiential Education in the Age of Neuroscience." Journal of Experiential Education 38 (1):73-95. https://doi.org/10.1177/1053825914547153.

Zull, J. E. 2002. The Art of Changing the Brain: Enriching Teaching by Exploring the Biology of Learning. Stylus Publishing, LLC, https://styluspub.presswarehouse.com/. 